\title{
Human Factors in the Design of Sustainable Built Environments
}

Scientific research provides convincing evidence that climate change is having significant impacts on many aspects of life. In the built environment domain, regulatory requirements are pushing the challenges of environmental, economic, and social sustainability at the core of the professional agenda, although the aims of carbon reduction and energy conservation are frequently given a priority over occupants' comfort, well-being and satisfaction. While most practitioners declare to embrace sustainability as a driver of their professional approach, a general lack of integrated creative and technical skills hinders the design of buildings centred on articulate and comprehensive sustainability goals, encompassing, other than energy criteria, also human-centred and ethical values founded on competent and informed consideration of the requirements of the site, the programme, and the occupants. Built environments are designed by humans to host a range of human activities. In response, this paper aims to endorse a sustainable approach to design founded on the knowledge arising from scholarly and evidence-based research, exploring principles and criteria for the creation and operation of human habitats that can respond to energy and legislative demands, mitigate their environmental impacts, and adapt to new climate scenarios, while elevating the quality of experience and delight to those occupying them.

Keywords: Human behaviour; Sustainable development; Intelligent building; Occupant comfort; Evidence-based design

Sergio Altomonte*, Peter Rutherford and Robin Wilson

Department of Architecture and Built Environment, University of Nottingham, University Park,

Nottingham, NG7 2RD, UK

*Corresponding author. Email: sergio.altomonte@nottingham.ac.uk

Received 9 February 2014; Accepted 22 September 2014; Published online: 27 Oct 2014.

Altomonte, S., Rutherford, P., Wilson, R., 2015. Human Factors in the Design of

Sustainable Built Environments: Special Issue: Workspaces Promoting Wellbeing.

Intelligent Buildings International. 7(4), 224-241 


\section{Sustainable Development and the Challenges of Intelligent Building Design}

\subsection{The Threats of Human-Induced Global Warming}

Climate conditions on Earth have been relatively stable over the last 10,000 years, providing the conditions for the development of settled human societies. Clearly, there have always been shifts in local weather patterns, but changes have occurred at such a pace that life forms could adapt or migrate. However, since the Industrial Revolution, humans have started to have a discernible influence on the equilibrium of the climate system, contributing to endanger, possibly in a non-reversible fashion, some of the conditions that had facilitated the flourishing of life (Altomonte, 2008a).

The threats of global warming have been widely accepted as a reality of our times. The Summary for Policymakers of the Working Group I contribution to the Fifth Assessment Report of the IPCC (2013) states that "human influence on the climate system is clear. This is evident from the increasing greenhouse gas concentrations in the atmosphere, positive radiative forcing, observed warming, and understanding of the climate system". The concentrations of carbon dioxide $\left(\mathrm{CO}_{2}\right)$, methane $\left(\mathrm{CH}_{4}\right)$, nitrous oxide $\left(\mathrm{N}_{2} \mathrm{O}\right)$, and other greenhouse gases $(\mathrm{GHG})$ in the atmosphere have progressively increased over the last two centuries, mainly due to combustion of fossil fuels, changes in land use, and intensive agriculture and farming (IPCC, 2013). The combined positive radiative forcing of changes in GHG concentration (i.e., how much these have caused a warming of the climate system) has been calculated in $+2,83 \mathrm{~W} / \mathrm{m}^{2}$ [with a likely range between 2.26 and 3.40] for 2011 relative to the year 1750. Conversely, the forcing induced by shifts in solar irradiance has been estimated in just $+0.05 \mathrm{~W} / \mathrm{m}^{2}[0.00$ to 0.10], hence providing evidence to the argument that the 'human factor' in global warming may be more significant than modifications of natural processes (IPCC, 2013). To limit further forcing, efforts have been devoted to define the thresholds in terms of GHG concentration that would prevent an irreversible human interference with the climate system. Several strategies could allow achieving the defined targets, although overcoming existing barriers - educational, financial, and political - may represent an arduous challenge. Nonetheless, even if limiting actions were put in place, climate models indicate that extreme events and changes in weather patterns would still be anticipated for the next decades due to the inertia of the climate system. For this reason, short-term adaptation strategies need to be developed alongside long-term mitigation measures so as to curb the consequences of human-induced climate alterations. 
To keep pace with the momentum of global warming, the agenda of sustainability in the design of human habitats can play a key role, considering that buildings contribute to over $40 \%$ of global energy consumption, and therefore - with the emissions they trigger - to the very causes of climate change (EEA, 2012).

\subsection{The Agenda of Sustainability in the Built Environment}

The extent of the impact to natural ecosystems, market demands, and legislative requirements, are all contributing to the awareness that the design of human habitats can make substantive responses to contemporary challenges. However, the principal difficulty in engaging with the agenda of sustainability in disciplines of the built environment is how best to interpret this often contentious concept (EDUCATE, 2012).

A Google search of the term currently provides over 40 million returns, yet its central meaning remains elusive, defying consensus beyond a relatively shallow one. By far, its most commonly cited characterization originates from the 1987 Brundtland Report, where the UN Commissioners asserted that development was to be considered sustainable if it "meets the needs of the present generation without compromising the ability of future generations to meet their own needs" (WCED, 1997). This is a core departing point, although it is important to scratch beneath the surface of this definition and question the actual relationship between sustainability 'rhetoric' in theoretical discourse, and its associated meanings and assumed benefits in practical applications.

In the built environment domain, this accentuates the risks of a 'deterministic' interpretation of the act of building design, whereas the labelling 'sustainable design' almost as a by-product of design itself - has been often deceptively associated solely with energy ratings, technical features, and $\mathrm{CO}_{2}$ reductions. Rather than providing a gateway to "holistic, open and flexible approaches", sustainability has been translated into mere "sustainabilization", a process by which fixed and limited indicators benchmark the success of the creation of spaces for human habitation (Rice, 2011).

Conversely, sustainable design should be assumed as the convergence of many disciplines into the design of low-carbon buildings informed by the needs of occupants, and in adaptive response to their environmental, economic, and socio-cultural context. This approach should be based on carefully considered design principles that treat the environment as a form generator, and adopt physical laws, informed by site specific data, as matters of spatial composition. This leads to the question of how to make building design progress sustainably, while mitigating impacts to the environment and 
adjusting to alterations in climate. To this aim, a starting point should be represented by the evidence-based exploration and understanding of the intricate behavioural settings inherent to the very ecosystem that nurtures, and literally sustains, human life.

Adaptive and responsive forms of life have long preceded the existence of mankind, maturing and fine-tuning their methods and techniques for survival. Biomimicry has always occurred in Nature to help organisms survive and adapt to their surroundings, a strategy for evolution that - today as in the past - is not unfamiliar to humans (Benyus, 1997). Not too long ago, in fact, humans learnt to respond to the contextual features of location and the availability of local resources basing the design and construction of their habitats - together as their behaviours - on a mutual relationship with their natural environment. Modern buildings, cities, and infrastructure can also be considered as a manifestation of adaptive and responsive evolution, although easy and immediate access to energy and resources has frequently caused the shifting of priorities from basic needs of survival to promoting a society of unsustainable excesses and consumerism.

Negotiating with the lessons from the natural world, and reconciling its connections with the ecological system, human development needs to sustain its path of economic, social, and cultural progress, doing more than simply 'not compromising' the needs of future generations, and effectively going "beyond biomimicry" (Turner and Soar, 2008).

\subsection{Intelligent Buildings or Intelligent Design of Buildings?}

Over the last thirty years, advances in mechanics and electronics, and growing collaboration between information technology, artificial intelligence, robotics, and construction engineering, have led to revolutionary changes in the building industry.

Concepts such as intelligent systems, smart materials, and building automation, inspired by the biological paradigms of self-adjustment, adaptation, and responsiveness, have made their way into the architectural debate, although with contentious results. As a matter of fact, not all uses of the biologically-inspired term of 'intelligence' have had the same legitimacy, and often such uses have been related mainly to promotion and marketing rhetorics. The legacy of 'intelligent building' has frequently been associated with mechanical control systems and actuators that can change their responses based on the variation of external and internal stimuli so as to maintain static conditions inside inhabited environments. This concept, however, only partially acknowledges that humans are physically, physiologically, and psychologically linked to a dynamic natural 
system, and this variability is one of the main triggers of the metabolic rhythm that guarantees their (transient) state of comfort (Clements-Croome, 1997, 2011, 2014).

Homo sapiens emerged around 250,000 years ago all through an evolution characterised by daily (circadian) and seasonal (circannual) cycles of environmental stimuli. Such dynamically changing conditions informed the regulation of sleep/wake periods, farming and hunting times, etc., while also entraining metabolic functions such as heart rate, blood pressure, body temperature, production of hormones, etc. In other words, exposure to cyclic variations in weather, seasons, and the day-night alternation provided the stimulation necessary to regulate the 'pulse' of human well-being and the pace of life: active outdoor at day, and resting under a shelter at night. Such tuning with environmental periodicities has constituted the only way of keeping human bio-rhythms in sync with those of Nature. However, since the Industrial Revolution, this natural pattern has been radically altered as a result of technological, socio-cultural, and economic factors. Moving away from the outdoors, humans today spend the greatest majority of their time in enclosed spaces, with significant drawbacks due to the shift from a dynamically-changing exterior to an artificially-controlled interior environment. As a consequence of the 'mechanical' rhythm that powers our modern economies and societies, human habitats require substantial amounts of energy to host 'artificial' activity shifts, depleting non-renewable resources and releasing harmful emissions. It follows that, at the very least, priority should be given to the design of buildings that do not detach human processes from the environmental stimuli that drive and govern them. Such necessity is also compounded by the need of creating spaces that can bring a positive contribution to the ecosystems with which they interact, demanding a radical reconsideration of the very criteria upon which designs are formulated.

To this aim, the paradigm of 'intelligent building' should be based on a richer approach than that to which it has, at times, been associated, i.e., the use of system automation, computer-assisted management, or active controls. According to Clements-Croome (2013), "intelligent buildings respond to the needs of their occupants and of society, they are functional and sustainable and promote the well-being of the people living and working within them". So, a building should be considered intelligent if it is designed to enhance the development of human activities, providing for the quality of life of its occupants, positively contributing to the ecosystem with which it engages in exchanges of matter and energy, and balancing the use of passive, active, or hybrid strategies depending on the climate and the material and immaterial demands of its occupants 
(Kroner, 1989). To achieve an intelligent sustainable design of human habitats, advances in knowledge and the results of evidence-based research can clearly play a major role by making viable methods, systems, and technologies that can exploit - at the scale of the building as at that of the city - clean and renewable energies without dangerous wastes and emissions, and fostering the value of experience for its occupants (Vischer, 2009). The challenge therefore consists in identifying, and transferring into the practice of design, methods by which advances in technology can be integrated with current building practices. Through the implementation of traditional and cutting-edge knowledge, built environments need to combine their programme requirements with those of environmental contexts, natural rhythms, socio-cultural needs, and climate scenarios, measuring technical choices with demands of occupants in terms of physical comfort, as well as physiological and psychological well-being and satisfaction.

\section{Design for the Occupant}

\subsection{Insight, Hindsight and Foresight in the Design Process}

An intelligent sustainable design of human habitats can foster major advantages to the quality of built spaces, minimizing impacts to the ecosystem, bringing benefits to its users, guaranteeing contact with the context, and offering stimuli conducive to health, attitude, mood, and possibly productivity (Veitch et al., 2007; Clements-Croome, 2006). Buildings can be considered as complex systems where the cooperation between its various constituents contribute to the metabolism of an interconnected whole. Clearly, occupants play a key role in the functioning of the built organism, hence it follows that users should be directly engaged in a scrupulous feedback loop before, during, and after the design process. The demands and aspirations of the occupants are crucial to inform the design of built environments from its early stages. Even assuming a 'reductionist', energy-centred, approach to the agenda of sustainability, the role of the users is key: built environments do not consume energy, occupants do! (Janda, 2011)

By looking back at pre-industrial and vernacular societies, it is interesting to note that the design of built environments has always been characterized by an intrinsic connection between the building and its users. Actually, the designer was often the owner himself; based on the availability of resources, buildings used locally-harvested materials; comfort was desired but not a prerequisite at all times, and often it was met with simple adaptive responses to the conditions inside built spaces (e.g., clothing). 
In the practice of contemporary design, conversely, the designer is rarely the inhabitant of the end product, does not experience daily life in it, and does not bear operational and maintenance costs. As a consequence, the engagement of occupants is often taken into account - if ever - only when the formal characters of a building have already been resolved. This profound disjunction between the design team and the end users is also emphasised by the ubiquitous presence of building services devised to further divorce the occupants from a dynamically changing external environment, whilst impacting on inflexible expectations in terms of comfort and lifestyle. Modern-day buildings have a very short design time, and are often driven by constraints and regulation (e.g., rating tools) that de-prioritize the user and push issues such as energy efficiency, certification, emissions, etc., as design priorities. Although these are clearly essential parameters, the upfront costs often determine the final solution, while the running and lifecycle costs are often overlooked, even if these are frequently much higher than the initial capital investment also with regards to business operation expenditures (e.g., salaries).

To reconcile the disconnection between the conception of the built environment and its inhabitants, evidence from scholarly and evidence-based research reveals the numerous and complex interactions that a design team should be aware of. The building might be complex, but its user base is even more complex and needs to be carefully valued and understood. Architects should move away from an idealised, myopic, or utopian view of design, or think of it as purely deterministic, i.e., as a mere function of solar geometry, heat flows, ventilation, etc. Conversely, buildings should be seen as 'behavioural settings', whereas behaviours are a product of a series of interdependencies (e.g., relationships between strategies) and transactions (e.g., engagement with those strategies) between the occupant (or groups of occupants) and the (internal and external) environment. The building needs to be treated as a series of interconnected constructs, and system thinking should be applied to the design process so as to create spaces that can inform the behaviour of those inhabiting them. This requires not only clear awareness of the techniques and strategies to be employed in the construction and operation of a space, but also an understanding of the program for the setting (i.e., what does the space need to provide, and who/what the building is designed for) and the standing patterns of behaviour that should take place within that setting.

Intelligent sustainable design should bring more value to a building than just aesthetics or energy savings. But for this, the design team needs to be involved early in the process and work with the client to understand the brief, timeframe, and budget, so as to meet 
aspirations, while producing an output - from a masterplan to a building interior - that is also pleasurable to work or live in, responsive to the environmental and socio-cultural context, resource efficient, and financially viable to build and operate (RIBA, 2011). Intelligent building design should provide workplaces that facilitate recruitment and retention of staff, encourage creativity and interactions, and engage employees in their activities (Altomonte and Schiavon, 2013). Spatial layout, indoor environmental quality, level of control, proxemics, etc., are all 'killer' variables that have been linked to occupant satisfaction, well-being, job performance, and productivity (Leaman and Bordass, 2006). Besides, designing with the user in mind can also turn a building into a tangible asset, influencing the corporate image, and securing higher rents and lower risk premiums (CABE, 2005). As an example of workplace design informed by the simultaneous consideration of brief, context, users, and building operation demands, the Council House 2 in Melbourne (Figure 1) adopted, from the outset, an integrated design strategy based on a charrette process, a two-week intensive workshop that involved the entire design team (and the client) working as a single unit. This participatory decisionmaking approach facilitated the resolution of technical and design decisions within a 'consensus-style' environment, bridging gaps between disciplines, and resulting in fewer setbacks later on in the project. Working with the constrained nature of the site and the desire of an open-plan office setting, the building has been conceived and built primarily to be comfortable and healthy for its occupants, whose physiology and experiential feelings - together with the target of significant energy savings - have been regarded as key-factors in every decision (Altomonte, 2005). 

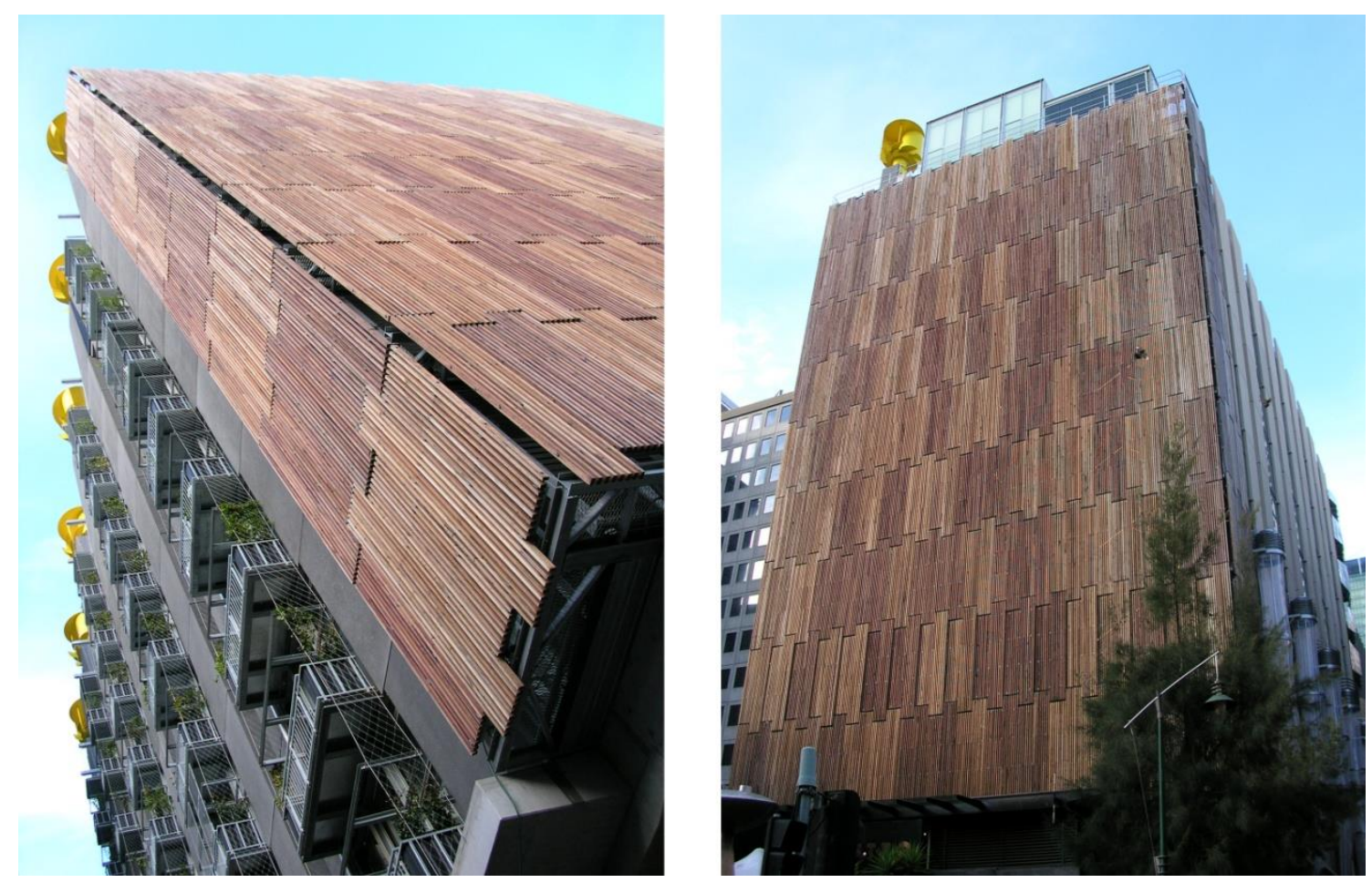

Figure 1. The Council House 2 in Melbourne (Australia). Source: Authors.

Also for other typologies, such as healthcare and educational buildings, an intelligent user-centred design can have significant impacts on the well-being of occupants. It has been demonstrated, in fact, that daylight, views of nature, fresh air, control of noise, and accommodation in single-occupancy rooms, can help speed up recovery times and reduce medication, while good spatial planning can maximise the time spent by nursing and medical staff with their patients (Lawson and Phiri, 2003). Likewise, design dictates the basic environmental conditions - air quality, luminous, visual, and acoustic comfort - that can support the quality of learning in an educational building, while the careful creation of break-out spaces can encourage informal conversations and the exchange of ideas, helping to build relationships, and facilitating discussions among (and between) teachers and learners. In addition, the design of educational buildings can also support the establishment of an identity to attract and retain staff and students, conveying an institutional ethos and ideals that can influence performance and social behaviour.

In this context, an interesting case in which aesthetics, culture, and communication of sustainable values have been comprehensively addressed is the Centre for Sustainable Energy Technologies (CSET) designed by Mario Cucinella for the University of Nottingham Ningbo campus in China (Figure 2). In this building, which provides laboratory spaces, offices, and seminar accommodation for academic staff and post- 
graduate students, the purpose of design aesthetics has been explored primarily in terms of its social functions and cultural benefits, promoting the role of design as a model of innovative construction, financial viability, and effective energy performance in practice. Inspired by Chinese lanterns and traditional wooden screens, the CSET China's first zero carbon university building - has been conceived as a 'beacon', a demonstrator of state-of-the-art techniques for environmentally responsible design and renewable energy technology that can inspire change and re-orient the building industry in a highly dynamic construction environment.
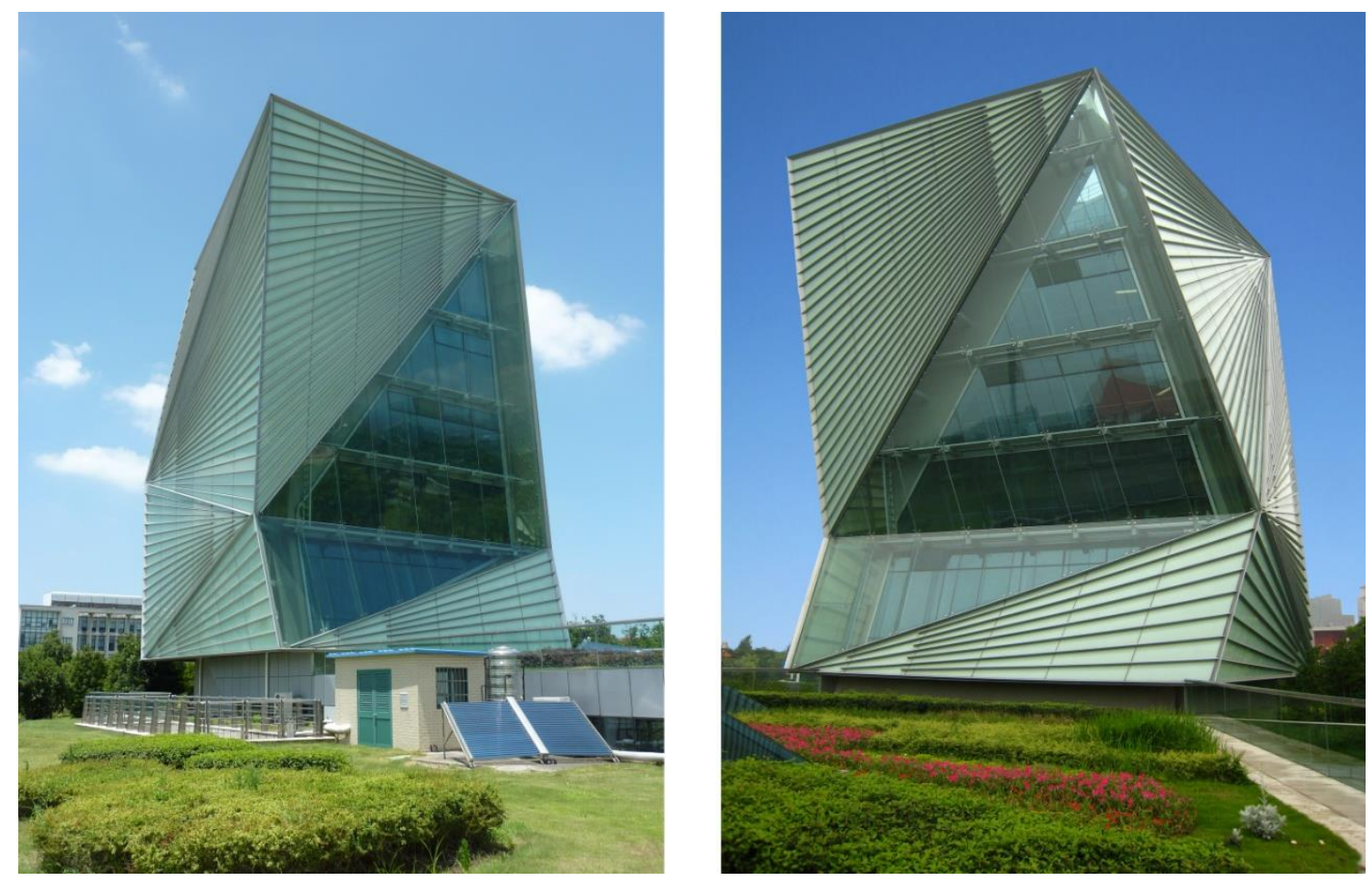

Figure 2. The CSET, University of Nottingham Ningbo (China). Source: Authors.

The quality of public spaces in cities can also have a direct impact on feelings of identity, belonging, civic pride, and personal safety (RIBA, 2011). In pre-industrial and vernacular times, people used to design and build their own urban habitats, responding to their demands, traditions, and lifestyles. Conversely, in current practices, homes and neighbourhoods are often planned without a set end-user in mind, but rather catering for an 'amorphous' entity with vague needs and socio-cultural aspirations. Intelligent cities design should harmonise "the plural processes of negotiating sustainable liveable places that, in addition to realising a visually pleasing townscape, critically satisfy social, functional, economic, technological and environmental requirements" 
(Clements-Croome, 2013). A user-centred design of urban environments should help to build strong societies, creating residential spaces where people feel secure and included (Halpern, 1995). Homes should accommodate their inhabitants in comfort, supporting flexibility (e.g., working from home), functionality, and entertainment. Their setting should provide a balance between private, semi-private, and public spaces, and encourage residents to interact with neighbours and strengthen the sense of community. Among several exempla, the 8 Tallet and VM Mountain in Ørestad, Copenhagen (Denmark) - regardless of the debate on the actual success of the masterplan (Olsoon and Loerakker, 2013) - were designed by Bjarke Ingels Group to offer all the 'ingredients' of a lively mixed-used neighbourhood, where different functions can coexist. 8 Tallet (Figure 3) is a an alley of 476 houses of various typology - apartments, penthouses, and townhouses with private gardens - as well as office spaces and communal facilities, connected by a continuous promenade and cycling path that 'twists' from street level to the $10^{\text {th }}$ storey around two green courtyards, where social life, the extemporaneous encounter, and residents' interactions are fostered.
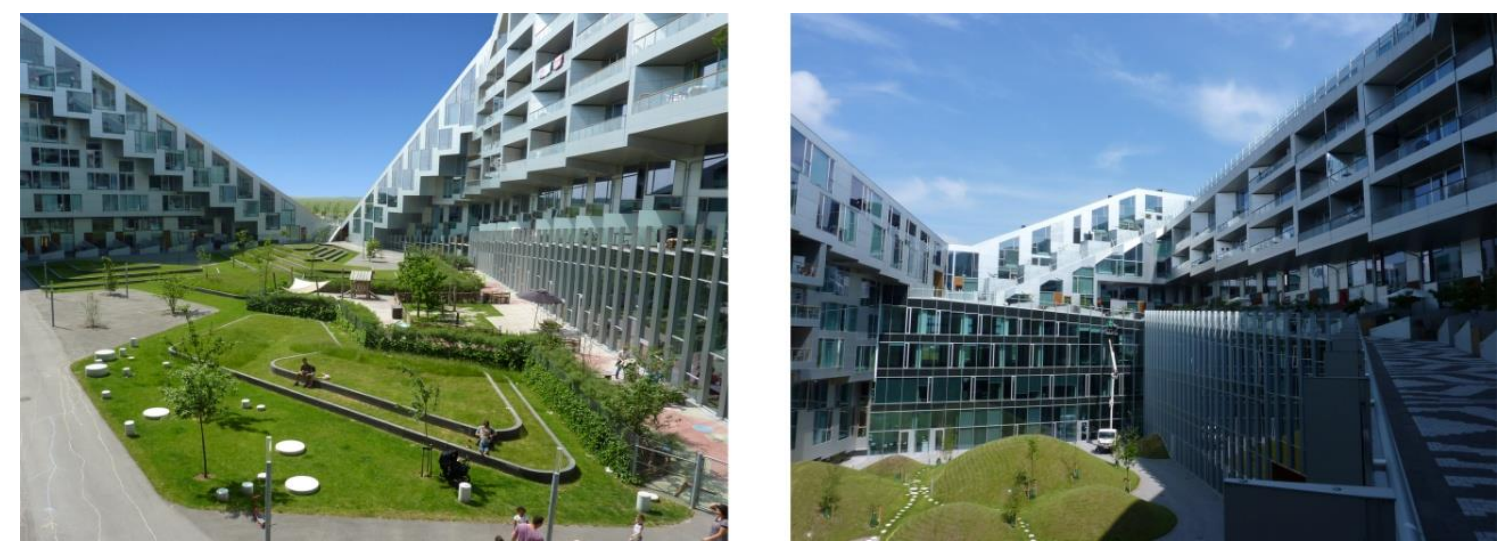

Figure 3. 8 Tallet in Ørestad, Copenhagen (Denmark). Source: Authors.

VM Mountain (Figure 4) features 80 housing units all with their private deck and roof garden offering access to sunlight, fresh air and views, while changing the 'character' of the building according to the seasons. Residences are arranged above a multi-storey public car park, hence creating a concrete 'hillside' that symbiotically combines the serenity and tranquillity of suburban life with the social intensity of urban density. 

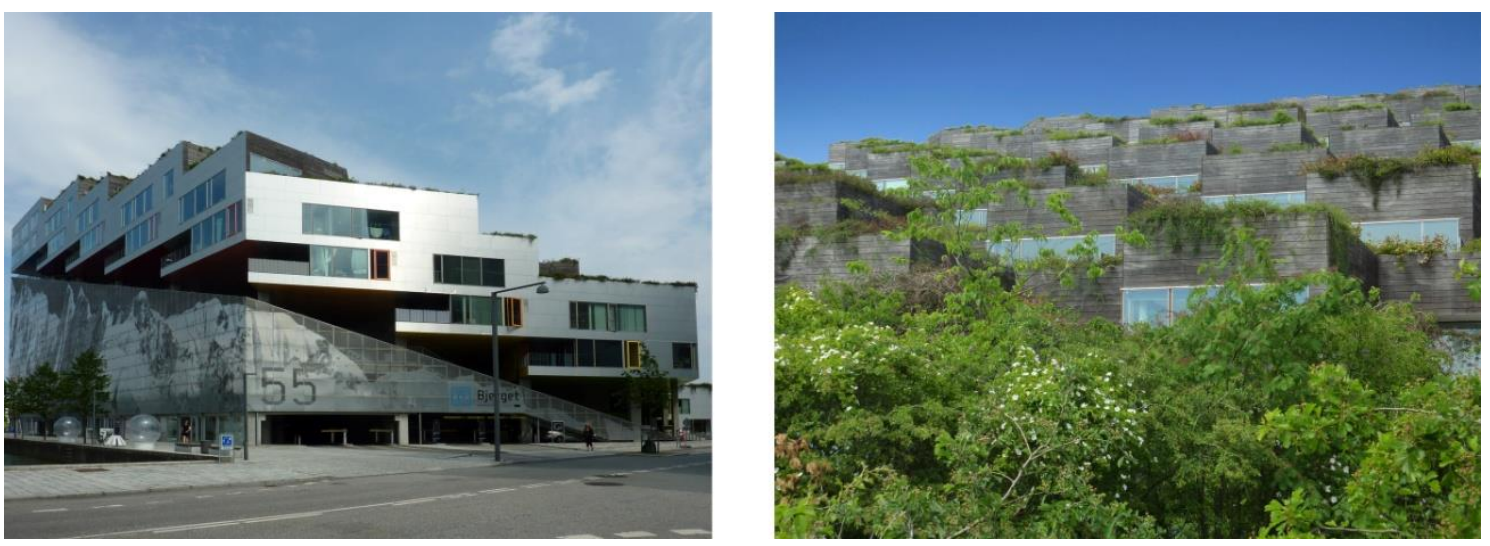

Figure 4. VM Mountain in Ørestad, Copenhagen (Denmark). Source: Authors.

In essence, intelligent sustainable design should be associated to an attention to the basic principles of how human 'agents' respond to their environment, how the environment in return responds to their interventions, and how to provide for the comfort and well-being of those that occupy a built space (Robinson, Wilke and Haldi, 2011). The design team is thus faced with considerable challenges, particularly when it has to address at once the - often contrasting - needs of clients and users, the economics of building, and the numerous technological options currently available. To meet this task, it is essential to consider the importance of hindsight, insight, and foresight in the design, construction, and operation of a built space. This should start from learning from precedents, and reflecting on outcomes that can inform the design process (hindsight), for then understanding those who are going to occupy and manage the building (insight). But the challenges do not end with the design process, since the various interrelationships between the systems that compose the built organism should be appraised via pre- and post- occupancy assessment evaluation (foresight), so as to monitor, measure, and provide feedback to inform the operation of the building and guide future designs. In this, the use of appropriate tools can support the creation of new knowledge that can steer the design: before it is conceived to clarify objectives, assess options, and set performance targets; during the design and construction process, to facilitate decision-making and fine tuning responses; after the occupation, to set operational targets and compare design predictions with actual performance.

The agenda of sustainability should motivate the design team to go beyond the 'technicist' issues of energy consumption and emissions, and engage with a deep understanding of the building's programme, the site, and the occupants, and how they interact as a complex system. Obviously, among the interactions that the design should 
interrogate, those in the visual, aural, and thermal physical domains play a key role.

\subsection{Perception and Physiological Entrainment in the Visual Environment}

For their survival, humans need to maintain with the environment a series of energetic exchanges to keep homeostatic conditions in response to a dynamically changing surrounding context, and trigger their metabolic processes (Worall, 2011). Among the natural forms of energy that can provide the body with physical, physiological, and psychological stimulation, daylight - with its variations in intensity, distribution, and spectral composition - can foster the comfort and health of building occupants. If properly designed, a daylight strategy can also afford energy savings, as long as it reduces need for artificial lighting, is managed accordingly with thermal needs (e.g., solar gains and heat losses through windows) and avoids glare and other visual discomfort (e.g., reflections or contrast). Further to this, the careful ingress of daylight in buildings can create meaningful experiences, dictating the moods and the quality of a space, telling about functions, place and climate, indicating the passing of time, underlining shapes, disclosing materials and textures, marking the boundary between inside and outside and between spaces, providing orientation, a focus, a hierarchy, encouraging movement or concealing a symbolism. Daylight can play a key role in creating an ambience that responds to occupants' expectations (aesthetics, ergonomics, etc.) and demands (privacy, concentration, details, etc.), while facilitating perception and expressing a meaning (Altomonte, 2008b). Daylight also impacts strongly on the human perceptual system via the view that it is often associated with, offering relief from the muscle strain linked to repeated visual tasks, while supplying environmental stimuli, connection with the surrounding, relaxation, and orientation in space and time (genius loci) that are beneficial for mood and social behaviour. Nevertheless, windows remain one of the most complex building components to design. They can bring light, fresh air, protect from rain, noise, etc., but, at times, excessive luminous permeability can cause visual and/or thermal drawbacks, or lead to a loss of privacy. The balance among these factors also varies continuously throughout the day and with the seasons.

A daylight strategy fostering at once delight, energy efficiency, comfort, health, and well-being has to find a balance between various diverging requirements. Quantitative variables (e.g., luminance, illuminance) have to be measured with qualitative and behavioural factors, and with individual preferences (Boyce, 2003). Photobiological research, for example, has demonstrated that daylight, other than providing vision and 
spatial/colour perception, has also a non-visual effect that regulates metabolic processes (Veitch, 2005). When light (energy flux) is projected on the retina, its stimulation (nervous impulse) is transmitted not only to the main visual areas of the brain (interpretation) but also to the suprachiasmatic nucleus $(\mathrm{SCN})$ in the hypothalamus, responsible for hormonal regulation (Boyce, Hunter and Howlett, 2003). Visible radiation hence triggers all the physical, physiological, and psychological responses that characterise the surrounding environment and regulate the metabolism of the body. Exposure to daylight at specific times of the day contributes to synchronise the circadian clock, stimulates blood circulation, enhances the secretion of vitamin D, favours the absorption of chemicals in the body, regulates protein metabolism, and controls the secretion and suppression of hormones such as serotonin (dictating mood, appetite, memory, etc.), dopamine (linked to the regulation of blood pressure, body temperature, and heart rate), cortisol (aiding in the assimilation of fat, proteins, and carbohydrates) and melatonin (distributing temporal information to the body).

Until relatively recently, all these processes were attributed uniquely to the two known 'visual' photoreceptors in the human eye: the cones, which guarantee colour vision in bright luminous conditions (photopic), and the rods, regulating monochromatic visual information in dim environments (scotopic). However, Berson, Dunn and Takao (2002) detected a third cell-type photoreceptor - the 'intrinsically photosensitive retinal ganglion cell' (ipRGC) - that governs metabolic processes and has its own neural connections to the pineal gland (where melatonin is produced) and the $\mathrm{SCN}$, the brain's biological clock. The ipRGC has properties different from cones and rods in terms of sensitivity, temporal response, and time of exposure, and as regards to demands of spectral composition, intensity, and duration of the visual signal for regulating physiological functions. These findings are leading to reconsider the design of luminous environments that can enhance visual and metabolic processes (Van Bommel, 2006).

First of all, although humans are adapted to large outdoor illuminance and dynamic changes in daylighting levels, interior lighting practice mostly seeks to provide constant illuminance at day and night, and with an intensity considerably lower than outside (Brainard et al., 2001). In second instance, the triggering of hormone secretion in the body and other metabolic functions require temporal variations in the Correlated Colour Temperature (CCT) of the luminous stimulus, although current artificial lighting systems are generally adjustable uniquely in output levels and tend to maximise their lumen/Watt output based on the sensitivity of the photopic vision (Begemann, Van den 
Beld and Tenner, 1997). Thirdly, daylight is extremely variable in intensity, spatial distribution, and direction, and the human body needs to maintain experience of such changes. Finally, the timing and the duration of light exposure should also be considered, since luminous entrainment should follow the biological rhythms of the body to avoid temporal advances or delays (Rea, Figueiro and Bullough, 2002).

In summary, light can influence the ocular performance and the well-being of occupants through not only luminous but also perceptual and circadian factors, which have to be appropriately considered to simultaneously meet the energy demands of the building, as well as the complex functional and biological needs of its users. Daylight should render the spaces lively, activating, and motivating, and provide appropriate stimulation to support the human circadian rhythm, telling about the time of the day, the season, and the weather, and addressing aspects related to society and culture. Yet, these design choices have to be balanced with the risk of excessive thermal gains, glare, and other luminous discomfort. 'Human' lighting criteria, in essence, should take into account at once visual and non-visual factors - contrary to current standards whose recommendations are often solely related to static photopic sensitivity - so as to guarantee adequate energy management and foster sensible 'enlightenment' for users.

\subsection{Health and Well-being in the Aural Environment}

The aural environment plays a substantial role in human satisfaction with built spaces, with authors such as Truax (2001) suggesting that listening is a "crucial interface between the individual and the environment". As a sensory mode, it helps us to communicate, feel part of the everyday world, and warn us of danger (Bull, 2004). However, it is also mooted that it involves a "set of sophisticated skills that appear to be deteriorating with the technologized urban environment, both because of noise exposure, which causes hearing loss and physiological stress, and because of the proliferation of low information, highly redundant, and basically uninteresting sounds, which do not encourage sensitive listening" (Truax, 2001). Considering the importance of sound and the aural environment on our everyday life, it is surprising to note that all too often many acoustic situations are rarely designed, yet their impact on those who occupy them is undeniably significant. Given the dialogic relationship between people and environment, it is essential that acoustics are given due attention by the design team. Findings from research have proven that improper consideration of acoustic factors strongly impacts on those experiencing them. In their report on the Healing 
Environment within healthcare facilities, the UK's Department of Health concluded that "wounds take longer to heal when patients are exposed to noise for long periods" and "noise can also affect our weight and our hormonal balances" (DoH, 2005). Indeed, it is well known that sound (noise) can significantly disempower individuals and, as a result, have widespread personal and societal consequences (Salonen and Morawska, 2013). As a key contributor to general health problems, it is understood to induce both physiological and psychological harm (Kryter, 1985) and, in so doing, place considerable stress on the core services trying to support those affected.

The noise problem itself is surprisingly pervasive, and a European Environment Agency (2003) study suggests that about $16 \%$ of the total European population is distressed directly by it, and that about $10 \%$ suffer from severe sleep disturbance due to night-time transportation noise, with a general decrease in sleep quality and morning alertness (Passchier-Vermeer et al., 2002). Reports from the healthcare profession are particularly alarming, where for example noise-induced stress has been cited as a contributor to burnout and psychosis in intensive care units (Topf and Dillon, 1988). Beyond the implications for the individual, such problems have a major cost also to industry through illness, absenteeism, and a reduction in workplace efficiency, and to the healthcare systems through noise-related admissions, therapy regimes, and medication. Whilst extensive legislation exists that seeks to protect building occupants (such as the UK's HSE Control of Noise at Work Regulations, and the European Commission's Environmental Noise Directive) and restrict the sound transmission through adjacent spaces (such as Approved Document E within the UK's Building Regulations), all too often it seems that the design team does not either seize the opportunities afforded by good acoustic design, or appreciate the impact that inconsiderate design may have on the inhabitants. Yet, in most cases, the designer is in control of some of the fundamental variables that affect the acoustic environment, and has the power to anticipate and respond in an appropriate manner. The onus is therefore on the design profession to rise to such challenges. It can reasonably be argued that the majority of good acoustic strategies themselves are not overly complex, and fortunately there has been significant development in guidelines that have largely transformed key approaches adopted by design professionals towards the formation of adequate aural settings. In the main, such approaches are not revolutionary and simply require the design professional to be more aware of noise management and abatement strategies, such as the siting of buildings in relation to other noise-related activities, the planning of noise sensitive and/or critical 
zones and associated buffering strategies, the design of architectural elements such as sound insulation and isolation, and the creation of spaces suitable for the tasks at hand. Fortunately, the profession is beginning to respond to some of the opportunities afforded by acoustic design. Reflecting on the UK's Department of Health's study, it suggests that "courtyards and landscaped gardens close to patient areas should include plants that encourage songbirds". This is based on the principle that "sounds such as rain, a breeze, the sea, moving water and songbirds can calm and create a sense of well-being by triggering the release of endorphins, the body's natural opiates" (DoH, 2005). Indeed, it goes on to suggest, for example, that "music can have an analgesic or painkilling effect, and can also reduce blood pressure, heart and respiration rates". This is reflected in modern treatment regimes, where music therapy plays a critical role in the cure of depression or in non-medicalised calming and relaxation of agitated psychiatric patients. In other words, the use of sound can, at times, be a positive compliment or alternative to drug-based treatments and symptom management, and may allow those within hospitals to recover more quickly. Nonetheless, designers must be aware of inter-individual differences with respect to human comfort and preference one man's sound may be another man's noise - raising once again the significance of insight and foresight when dealing with issues such as sound management and control. Designing buildings is as much about 'sculpting' the aural environment as it is about 'shaping' visual and thermal forces. Whilst the acoustician is well placed to understand the importance of ensuring that lecture theatres are designed to be 'intelligible', or that concert halls provide acoustical 'richness' or 'envelopment', it is phenomena such as these that should be incorporated into the 'holistic' design of built spaces. Environmental and behavioural psychology has shown the intrinsic link between people's behaviour and the setting that they inhabit, and acoustic environments are no different to this (Blomkvist et al., 2005). Indeed, Garrioch (2003) clearly hypothesises that sound and acoustics help to forge a sense of 'belonging' and give a 'feel' to a place, thus appearing "to root the user in the world with a force that differs from those of the other senses" (Bull, 2004). This much forgotten connection between people and aural environment is evident in the way a young child shouts out in a large space to listen to their 'echo', the way people lower their voice when entering a place of worship, or the ways musicians use the acoustic environment as an 'instrumentarium' (Augoyard and Torgue, 2008), an extension of their musical instrument thereby adapting their performance to the space where they are playing. 
Human relationship with aural stimuli goes beyond basic acoustic comfort and involves a series of, highly complex, personal, social, situational, and symbolic transactions that, whilst innately understood, are often not consciously attended to. It is imperative therefore that the design team seeks to equally respect the importance of acoustical design as they would aesthetic features or other factors driving occupants' comfort.

\subsection{Control and Adaptation in the Thermal Environment}

The definition of human thermal comfort, based on the notion of homeostasis, serves as a relatively simple model around which the supporting role of the building, its services, and controls may be cast. In very broad terms, the thermal environment required to achieve homeostasis resembles a heat sink, typically quite shallow in nature, which presents a temperature gradient along which metabolically generated heat may flow. Provided the gradient is such that the flow matches the metabolic rate of heat generation, the body temperature remains stable and it is assumed that thermal comfort is attained. The relationship between the building and the environment within which it sits may be set out along similar lines. In seeking to maintain the conditions for homeostasis - and hence thermal comfort - the building itself serves as either a sink or a source that drives (or draws) flows of heat to and from the external environment. If left unchecked, these flows tend to level out thermal gradients, and the conditions inside the building begin to approach those of the outside. These are the conditions that would have prevailed within that space prior to its enclosure by the building envelope - the conditions from which the building seeks to protect the occupant (Humphreys, 1978).

The internal building environment thus serves as an intermediary setting, maintaining the conditions required for homeostasis through the use of active and passive strategies that manipulate energy exchanges with the constantly changing external environment. In seeking to implement these strategies, use is frequently made of a control system that monitors the internal environment and then modifies the manner in which the building and its services operate to ensure that the comfort needs of users are met.

In practice, this frequently means that a simple thermostat serves as a 'human proxy', providing the control system with an indication as to the adequacy of the conditions it is maintaining on behalf of the occupant. While the quantity being monitored (usually, dry bulb room temperature) is unarguably key to achieving human thermal comfort in the majority of cases, it is difficult to effectively represent the full range of energy exchanges that occur between occupant and environment, and relay these back to a 
control system. In addition to being numerous - involving a host of conductive, convective and latent exchanges - the paths via which the heat travels are also likely to be location-specific, varying in strength depending upon where the occupant is. If it is also considered that, within a population, no two individuals are likely to share the same view as to what constitutes the 'ideal' comfort, and what is deemed comfortable varies with time, it becomes clear the great deal being asked of a control system.

Improvement in our understanding of human thermal comfort - and development of models such as the Predicted Mean Vote (Fanger, 1970) or the Adaptive Comfort approach (de Dear and Brager, 1998) - provides a good starting point upon which the decision making process implemented within a control system may be based. It is probable that the use of sensors will continue to serve as a key means by which the conditions within the building are fed back to the control system. There is, however, scope to increase the number of variables that are monitored, and to gain improved spatial resolution to reflect the variety of conditions that prevail within the space. While developments of this nature start to offer the ability to better understand the internal environment and affect more precise control, there is still a pressing need to consider the relationship between the control system and the occupants of the building it serves. The association between cause and effect (the occupant requesting a change and the building responding) may be reasonably easy to establish in buildings with a small population where the occupant can make changes to a control system, but the feedback can become very difficult with more diverse settings, where control is vested in building managers, located remotely from the conditioned space and hard to contact directly. Inability on the part of occupants to effect change when the internal environment does not meet their comfort needs, especially if on a recurrent basis, can result in persistent dissatisfaction with the building and its systems, even within what might otherwise be an appropriately-maintained living setting (Brown, Dowlatabadi, and Cole, 2009).

Creating opportunities to engage the occupant and the building in a 'conversation' is perhaps one way forward to not only empower the users of the space, but also harness them to provide a highly sophisticated, distributed, 'biosensor' apparatus. The human thermoregulatory system aims to achieve homeostasis, and the notion of discomfort may be thought of as messages sent out to initiate physical changes when homeostasis is not being achieved. Understanding if and why occupants are uncomfortable can enrich the data provided by conventional sensors and implement more 'intelligent' control strategies. The means by which this may be achieved offer yet more useful information. 
In this context, computing devices running bespoke 'apps' offer a channel along which communication with a building control system might take place. They also offer a way by which the location of the occupant within the building may be established and the spatial significance of the information they are providing determined. Strategies for informing how the building 'replies' are not trivial, especially when the conversation might take place with multiple occupants, each with different expectations. The lessons from buildings where conversations were not possible, either because they could not be initiated or since the building operated in 'listening mode' only, suggest this is a key process in closing the control loop. Part of this conversation may see control systems not only mediating the thermal environment, but also seeking to respond to - or anticipate - the actions exercised by occupants (Cole and Brown, 2009). This is one way in which the disparate comfort needs at the extreme ends of a population of occupants might be met within what necessarily may be an environment tailored for the majority. Implementing such a strategy is likely to lie in the social domain, specifically the management of organisations using the building. This needs to create an environment where the conversation between the building and its users can incentivise behaviours complementing the strategies overseen by the control system. The most obvious examples would be through dress codes that provide occupants the freedom to add or remove clothing and, in so doing, adjust the flow of heat to the moderated internal environment. Given that the benefits of effective control are likely to result in reduced utility bills and/or improved productivity, target setting is one strategy where monetary return could be used to trigger powerful incentive, either at the level of the individual, or through developing social norms and peer pressure.

The approach outlined implies technical development in terms of processing large volumes of data and deciding on appropriate responses. Perhaps more importantly as regards to its acceptance, are the knowledge/technology/organisation interfaces between those who design and control the building and the adaptive behaviour of its occupants. A systems-based approach to the problem may likely yield the richest way forward.

\section{Promoting the Intelligent Design and Occupation of Buildings}

\subsection{Occupants' Comfort and Adaptive Behaviour}

An intelligent sustainable design of the built environment, centred on the requirements of the building and the needs of its occupants, is a key factor for addressing the 
challenges that mankind is facing as regards to environmental impacts, reduction of energy dependency, management of resources, and climate change, whilst also safeguarding the health and well-being of those that live and work within buildings. To support these complex tasks, simulation of building performance at design stage is today being increasingly used in professional practice to predict comfort of occupants and energy budgets in operation. However, although the computational features of simulation tools are relatively mature, buildings' operational energy is often higher than design predictions, whereas occupants are seldom comprehensively satisfied with the indoor environmental quality of the spaces they inhabit (Schiavon and Altomonte, 2014). One of the sources of these discrepancies is represented by the limited ability of simulation tools to cumulatively represent and model factors related to users' stochastic behaviour and their interactions with the environmental forces surrounding them.

Building occupants exercise actions in response to internal and external environmental stimuli to achieve or maintain comfortable conditions according to the adaptive principle: "if a change occurs such as to produce discomfort, people react in ways which tend to restore their comfort" (Humphreys and Nicol, 1998). At a personal level, actions can be behavioural (e.g., adjustment), physiological (e.g., acclimatisation), and psychological (e.g., habituation) (Brager et al., 2004). Yun and Steemers (2008) have also characterised the behavioural category as: spatial, e.g., variation of use patterns, relocation of activities; personal, e.g., change in clothing, activity, posture, beverages; and, control, e.g., windows, blinds, lighting, fans, etc. The adaptive principle suggests a feedback mechanism between environmental and contextual factors - e.g., alterations of functions over time - and users' behaviour (Haldi and Robinson, 2008, 2011).

As outlined above, scientific research provides evidence that occupants' comfort is directly affected by physical variables (i.e., light, sound, heat) but can also be influenced by other factors independent from conventional measures of indoor environmental quality, that include views, building features, level of control, etc. Physiological and psychological studies indeed reveal that the perceived sensation of well-being is a composite state involving an overall response to a combination of stimuli. Environmental forces result in actions and/or evaluations that lead to mental and physical effects through the main regulation systems of the human body (nervous, immune, and endocrine), but also cause changes in physiological and psychological states (Lehman, 2011). However, due to individual preferences and requirements, 
people are intrinsically different in their reaction to a set of variables and do not respond disjointedly to a complex mixture of environmental stimuli (Bluyssen, 2010, 2013).

In essence, programmatic, technological, environmental, and behavioural factors can all influence the perceived sense of comfort, well-being, and satisfaction of building occupants, and these relationships should be comprehensively considered at the design stage - as well as throughout the operation of built environments - as resulting from more than simply the average of physical parameters (Baird, 2011), while also involving complex and dynamic social and cultural constructs characterised by different meanings related to distinct living spheres (Chappels, 2010). Such awareness is bringing new challenges to all the professions involved, directly or indirectly, in the building industry, demanding that knowledge, skills, and competence of energy efficiency are supported by an understanding and appreciation of the various factors that can impact on the quality of life of people, responding to programmatic requirements within an ethically, culturally, and socially viable design process. This represents a major shift in the way in which the design practice is informed by education and training, and the continuing professional development of building practitioners (EDUCATE, 2012).

\subsection{Professional Competence and Dissemination of Knowledge}

The position of the built environment in the context of the current climate (and economic) crisis is triggering demands for design professionals with multidisciplinary skills, ranging from creative design to technical abilities. For sustainability to be embraced within an integrated design process - and facilitate an in-depth understanding of contemporary challenges - the education of professionals should move away from 'reductionist' conventions to foster critical thinking, building systemic connections between disciplines, and promoting lifelong learning. The multifaceted complexities of motivation, attitudes, and ethos also impact upon successful education of - and for sustainability. Further, the adoption of a sustainable design approach in professional practice needs to be supported by subject benchmarks and regulatory frameworks, whose requirements are still often ambiguous and inhomogeneous. As a matter of fact, although most firms would declare to embrace sustainability as a focus of their activity, with relatively few exceptions - some exempla of which have been previously illustrated - a lack of integrated creative and technical skills results in a profession yet ill-equipped to handle the paradigm shift required by sustainable design. To this day, there is an increasing legacy of buildings deficient of sound sustainability goals, while 
design approaches where carbon neutrality has been prioritised over design inspiration and users' well-being hinder the architectural value of the spaces produced, and the delight they bring to those inhabiting them (Altomonte, Rutherford and Wilson, 2012). New pedagogical methods and a substantial revision of professional training and regulatory frameworks are hence needed to surmount existing barriers, and facilitate dialogue between scientific research and the creative implementation of sustainability in design practice. Such considerations yield profound impacts also on the way in which awareness of intelligent and sustainable design of buildings is transferred to end-users.

Dissemination of knowledge to the public is, in fact, of paramount importance to prevent misconceptions, cultural prejudices, and reticent mindsets that prioritize savings at the time of investment rather than valuing returns over time. Mitigation of impacts, and adaptation to variations in local and global climate, therefore require efforts in every sector of human activity, from the legislative - involving policies, technologies, and management procedures - up to the personal sphere. These should underpin a commitment and understanding of sustainable principles and values, so as to trigger changes of attitude and expectations in the design and management of buildings, endorse behaviours that can be effective in reducing consumptions and emissions, stimulate ethical responsibility, and combat the deceptive practice of 'greenwash'.

\section{Conclusions}

The agenda of sustainability and the urgency of climate change are deeply altering the practice of designing, constructing, and inhabiting the built environment. Exploring scholarly and evidence-based research, this paper has argued that the knowledge needed for the intelligent and sustainable conception and operation of built spaces may already be with us, provided that such know-how is supported by awareness of the needs of the occupants in terms of physical comfort and physio-psychological well-being, and its role is valued and understood before, within, and after the design process.

Making systemic links between various disciplinary domains and reconciling the disjunction between the design team and the end-users, advances in technology can provide a significant contribution to minimise the impact of economic and social development on the ecosystem, while guaranteeing the connection between human habitats and the natural world. Yet, it is through the intelligent design and behaviour of users that buildings can integrate their functions with dynamic environmental forces and adapt to changes in climate, adopting contextually-appropriate operational strategies 
that integrate passive, hybrid, and active techniques with site, functions, and occupants' requirements. The very concept of sustainability should move away from a set of targets to meet, transcending disciplinary boundaries and transferring knowledge between domains - e.g., architecture, physics, engineering, climatology, sociology, physiology, psychology, and natural sciences - to yield inspired design.

\section{References}

Altomonte, S. 2005. CH2 - Lighting and physiology. Australasian Journal of Construction Economics and Building, 5(2), 40-46.

Altomonte, S. 2008a. Climate change and architecture: mitigation and adaptation strategies for a sustainable development. Journal of Sustainable Development, 1(1), 97 112.

Altomonte, S. 2008b. Daylight for energy savings and psycho-physiological well-being in sustainable built environments. Journal of Sustainable Development, 1(3), 3-16.

Altomonte, S., Rutherford, P., and Wilson, R. 2012. Mapping the way forward: education for sustainability in architecture and urban design. Corporate Social Responsibility and Environmental Management, doi: 10.1002/csr.1311.

Altomonte, S., and Schiavon, S. 2013. Occupant satisfaction in LEED and non-LEED certified buildings. Building and Environment, 68, 66-76.

Augoyard, J.F., and Torgue, H. 2008. Sonic experience: a guide to everyday sounds. Montreal: McGill-Queen's University Press.

Baird, G. 2011. Did that building feel good for you? or - isn't it just as important to assess and benchmark users' perceptions of buildings as it is to audit their energy efficiency? Intelligent Buildings International, 3(2), 124-130.

Begemann, S.H.A., Van den Beld, G.J., and Tenner, A.D. 1997. Daylight, artificial light and people in an office environment; overview of visual and biological responses. Industrial Ergonomics, 20, 231-239.

Benyus, J.M. 1997. Biomimicry - Innovation inspired by Nature. New York: Perennial. Berson, D.M., Dunn, F.A., and Takao, M. 2002. Phototransduction by retinal ganglion cell that set the circadian clock. Science, 295, 1070-1073.

Blomkvist, V., Eriksen, C.A., Theorell, T., Ulrich, R.S. and Rasmanis, G., 2005. Acoustics and psychosocial environment in coronary intensive care. Occupational and Environmental Medicine, 62, 1-8. 
Bluyssen, P. 2010. Towards new methods and ways to create healthy and comfortable buildings. Building and Environment, 45, 808-18.

Bluyssen, P. 2013. What do we need to be able to (re)design healthy and comfortable indoor environments? Intelligent Buildings International, doi: 10.1080/17508975. 2013.866068 .

Boyce, P. 2003. Human factors in lighting. Troy: Lighting Research Center.

Boyce, P., Hunter, C., and Howlett, O. 2003. The benefits of daylight through windows. Troy: Lighting Research Center.

Brager, G., Paliaga, G., and de Dear, R. 2004. Operable windows, personal control and occupant comfort. ASHRAE Transactions, 110(2), 17-35.

Brainard, G.C., Hanifin, J.P., Greeson, J.M., Byrne1, B.,Glickman, G., Gerner, E., and Rollag, M.D. 2001. Action spectrum for melatonin regulation in humans: evidence for a novel circadian photoreceptor. Journal of Neuroscience, 21(16), 6405-6412.

Brown, Z.B., Dowlatabadi, H., and Cole, R. J. 2009. Feedback and adaptive behaviour in green buildings. Intelligent Buildings International, 1(4), 296-315.

Bull, M. 2004. Thinking about sound, proximity, and distance in western experience: the case of Odysseus's walkman. In Hearing cultures: Essays on sound, listening and modernity, edited by Veit Erlmann. New York: Berg Publishers.

CABE 2005. The impact of office design on business performance. London:

Commission for Architecture \& the Built Environment.

Chappells, H. 2010. Comfort, well-being and the socio-technical dynamics of everyday life. Intelligent Buildings International, 2(4), 286-298.

Clements-Croome, D. 1997. What do we mean by intelligent buildings? Automation in Construction, 6, 395-400.

Clements-Croome, D. 2006. Creating the productive workplace. London: E\&Fn Spon.

Clements-Croome, D. 2011. Sustainable intelligent buildings for people: A review. Intelligent Buildings International, 3(2), 67-86.

Clements-Croome, D., ed. 2013. Intelligent buildings: design, management and operation. London: Thomas Telford Publishing.

Clements-Croome, D, ed. 2014. Intelligent buildings: An introduction. Oxon: Routledge.

Cole, R.J., and Brown, Z. 2009. Reconciling human and automated intelligence in the provision of occupant comfort. Intelligent Buildings International, 1(1), 39-66. 
de Dear, R., and Brager, G.S. 1998. Developing an adaptive model of thermal comfort and preference. ASHRAE Transactions, 104(1a), 145-167.

DoH. 2005. The healing environment. London: Department of Health.

EDUCATE. 2012. Education for sustainable environmental design. Nottingham:

EDUCATE Press. http://www.educate-sustainability.eu/results-summary [Accessed

12 January 2014].

EEA. 2003. Europe's environment: The third assessment. Report No. 10/2003. Copenhagen: European Environment Agency.

EEA. 2012. Greenhouse gas emission trends and projections in Europe 2012. Report No. 6/012. Copenhagen: European Environment Agency.

Fanger, P.O. 1970. Thermal comfort. Copenhagen: Danish Technical Press.

Garrioch, D. 2003. Sounds of the city: the soundscape of early modern European towns. Urban History, 30(1), 5-25.

Haldi, F., and Robinson, D. 2008. On the behaviour and adaptation of office occupants. Building and Environment, 43, 2163-2177.

Haldi, F., and Robinson, D. 2011. The impact of occupants' behaviour on building energy demand. Journal of Building Performance Simulation, 4(4), 323-338.

Halpern, D. 1995. Mental health and the built environment. More than bricks and mortar? London: Taylor \& Francis.

Humphreys, M.A. 1978. Outdoor temperatures and comfort indoors. Building Research and Practice, 6(2), 92-105.

Humphreys, M.A, and Nicol, F. 1998. Understanding the adaptive approach to thermal comfort. ASHRAE Transactions, 104(1), 991-1004.

IPCC (Intergovernmental Panel on Climate Change). 2013. Summary for Policymakers. In: Climate Change 2013: The Physical Science Basis, edited by Stocker et al. Cambridge: Cambridge University Press.

Janda, K.B. 2011. Buildings don’t use energy: people do. Architectural Science Review, $54,15-22$.

Kryter, K. 1985. Effects of noise on man. New York: Academic Press.

Kroner, W.M. 1989. Intelligent architecture through intelligent design. Futures, 21(4), 319-333.

Lawson, B., and Phiri, M. 2003. The architectural healthcare environment and its effects on patient health outcomes. Report on NHS Estates Funded Research Project. 
http://www.wales.nhs.uk/sites3/documents/254/ArchHealthEnv.pdf [Accessed 6 June 2014].

Leaman, A., and Bordass, B. 2006. Productivity in buildings: The "killer" variables. In:

Creating the productive workplace, edited by D. Clements-Croome. London: E\&Fn Spon.

Lehman, M.L. 2011. How sensory design brings value to buildings and their occupants. Intelligent Buildings International, 3(1), 46-54.

Olsson, L., and Loerakker, J. 2013. The story behind failure: Copenhagen's business district Ørestad. http://failedarchitecture.com/the-story-behind-the-failure-copenhagensbusiness-district-orestad [Accessed 6 June 2014].

Passchier-Vermeer, W., Vos, H., Stembeklers, J.H.M., van der Ploeg, F.D., and Groothius-Oushoorn, K. 2002. Sleep disturbance and aircraft noise exposure: Exposure-effect relationships. Report 2002.027. Eindhoven: TNO.

Rea, M.S., Figueiro, M.G., and Bullough, J.D. 2002. Circadian photobiology: an emerging framework for lighting practice and research. Lighting Research and Technology, 34(3), 177-190.

RIBA 2011. Good design - It all adds up. London: Royal Institute of British Architects. Rice, L. 2011. Black-boxing sustainability. Journal of Sustainable Development, 4(4), 32-37.

Robinson, D., Wilke, U., and Haldi, F., 2011. Multi agent simulation of occupants' presence and behaviour. In: Proceedings of Building Simulation 2011, Sydney, 14-16 November.

Salonen, H., and Morawska, L. 2013. Physical characteristics of the indoor environment that affect health and wellbeing in healthcare facilities: a review. Intelligent Buildings International, 5(1), 3-25.

Schiavon, S., and Altomonte, S. 2014. Influence of factors unrelated to environmental quality on occupant satisfaction in LEED and non-LEED certified buildings. Building and Environment, 77, 148-159.

Topf, M., and Dillon, E. 1998. Noise-induced stress as a predictor of burnout in critical care nurses. Heart and Lung: Journal of Acute and Critical Care, 17(5), 567-574.

Truax, B. 2001. Acoustic communication. Westport: Ablex.

Turner, J.S., and Soar, R.S. 2008. Beyond biomimicry: What termites can tell us about realizing the living building. In: Proceedings of the First International Conference on Industrialized, Intelligent Construction, Loughborough University, 14-16 May. 
Van Bommel, W.J.M. 2006. Non-visual biological effect of lighting and the practical meaning of lighting for work. Applied Ergonomics, 37, 461-466.

Veitch, J.A. 2005. Light, lighting and health. Issues for consideration. Leukos, 2(2), 8596.

Veitch, J.A., Charles, K.E., Farley, K.M.J., and Newsham, G.R. 2007. A model of satisfaction with open-plan office conditions: COPE field findings. Journal of Environmental Psychology, 27(3), 177-189.

Vischer, J.C. 2009. Applying knowledge on building performance: From evidence to intelligence. Intelligent Buildings International, 1(4), 239-248.

Yun, G.Y., and Steemers, K. 2008. Time-dependent occupant behaviour models of window control in summer. Building and Environment, 43, 1471-1482.

WCED (World Commission on Environment and Development). 1987. Our common future. Brundtland Report. Annex to General Assembly document A/42/427.

Worall, M. 2011. Homeostasis in nature: Nest building termites and intelligent buildings. Intelligent Buildings International, 3(2), 87-95. 